\title{
The influence of affective cues on positive emotion in predicting instant information sharing on microblogs: Gender as a moderator
}

\begin{abstract}
Instant information sharing on microblogs is important for promoting social awareness, influencing customer attitudes, and providing political and economic
\end{abstract} benefits. However, research on the antecedents and mechanisms of such instant information sharing is limited. To address that issue, this study develops a research model to investigate the factors (affective cues in particular) that drive users to instantly share information on microblogs and explores the moderating role of gender. An online survey was conducted on a microblogging platform to collect data for testing the proposed research model and hypotheses. The results confirm the positive effects of informational (i.e., information uniqueness), ambient (i.e., information crowding), and social (i.e., social interactivity) cues on individuals' positive emotion, which subsequently promotes their urge to share information on microblogs. Moreover, the moderating effects of gender are identified. This study contributes to the understanding of instant information sharing from an impulsive behavior perspective. The results also provide important insights for service providers and practitioners who wish to promote instant information sharing on microblogs.

Keywords: Instant information sharing; impulsive behavior; urge; affective cues; gender difference 


\section{Introduction}

Microblogs (e.g., Twitter) are proliferating across various domains largely due to their support of instant information sharing (Castillo et al., 2013). Compared with traditional social media platforms (e.g., discussion forums and blogs), microblogs allow users to create and disseminate content, information, and opinions more widely and quickly, almost as soon as they experience an event (Cambria et al., 2016; Tobias, 2011). For instance, Twitter, an information network that uses interest graphs, has been described as the 21st century's newspaper (Wexler, 2014). Statistical reports indicate that $86 \%$ of Twitter users use the platform for news, with $74 \%$ of them doing so daily (Rosenstiel et al., 2015). To keep up with the news, $40 \%$ of Twitter users use the platform to be alerted to breaking news. Microblogs have increasingly become a crucial way to enhance situational awareness and obtain a better global picture of events (Tobias, 2011), not only in terms of social issues, but also financial and political issues (Lee \& Ma, 2012).

To achieve these benefits, microblogs have continuously encouraged their users to contribute timely and useful information to promote social awareness (Wang et al., 2015). It has been recognized that instant information from social media can enable users to effectively solve problems, share experiences, and store memories (Wang et al., 2012). Large-scale, real-time information sharing is critical for the development and maintenance of microblogs (Kwak et al., 2010; Munar \& Jacobsen, 2014; Wang et al., 2013). However, most users contribute hardly any information after their initial use: the top $15 \%$ of Twitter users contribute around $85 \%$ of all tweets (Richter, 2013), 
and more than $40 \%$ of Twitter users never tweet, only following other people's tweets (Brain Statistic Research Institute, 2015). In other words, there is relatively low "real-time" use of social media for content sharing (Munar \& Jacobsen, 2014). Hence, it is crucial to understand and capture what drives individuals to instantly share information on microblogs (Lee \& Ma, 2012; Stieglitz \& Dang-Xuan, 2013).

Despite this emerging trend of instant information sharing, this issue has received little theoretical and empirical research attention (Malik et al., 2016; Wang et al., 2015) and the limited number of existing studies tend to merely use descriptive approaches or content analysis (Nagarajan et al., 2010; Sakaki et al., 2010; Wang et al., 2012). The underlying mechanism of instant information sharing has yet to be empirically verified. To fill this research gap, the first objective of this study is to investigate the antecedents that influence users' to instantly share information on microblogs, with particular attention given to emotion as a potential driver. Typically, instant information sharing occurs when individuals experience an unplanned situation suddenly and thoughtlessly (Bermingham \& Smeaton, 2010; Tobias, 2011). There is then a continuous loop of interaction between users and the social media environment that generates spontaneous, unstructured, and multi-faceted user responses (Rosso et al., 2016). Moreover, information sharing on microblogs always conveys individuals' emotional state and the intended emotional communication (Bollen et al., 2011), which might trigger a high level of arousal and information diffusion (Stieglitz \& Dang-Xuan, 2013). Hence, we propose that microblogs provide and reinforce affective cues (environmental signals that can influence emotions) 
through which instant information sharing can be more emotional and impulsive, and less rational and deliberate.

Moreover, the relative effects of these antecedents in predicting information sharing in microblogs are likely to be contingent on individual characteristics such as gender (Walton \& Rice, 2013; Zhang et al., 2015). Gender differences have been extensively investigated in various decision-making processes, including information sharing (Holmberg \& Hellsten, 2015; Lu \& Hsiao, 2009; Taylor, 2004). However, previous research suggests that the contingency of gender differences in technology use depends on the nature of the technology and the usage settings (Venkatesh \& Morris, 2000; Zhou et al., 2014). Hence, caution is needed when extending previous findings regarding traditional information sharing behavior (as a reasoned action) to the context of instant information sharing in microblogs (as an impulsive behavior). Given the research gap on this issue, the second objective of this study is to investigate the role of gender differences in individuals' instant information sharing behavior on microblogs.

The remainder of this paper is organized as follows. First, we provide a review of the literature relevant to instant information sharing in microblogs. Next, we develop the research model and propose the associated hypotheses. This is followed by a description of the methodology, data analysis, and results. Finally, we conclude with discussions on the implications for both theory and practice, as well as the limitations and directions for future research. 


\section{Theoretical background and research model}

\subsection{Instant information sharing in microblogs}

Unlike sharing professional knowledge or past experience, information sharing on microblogs tends to be temporally and cognitively constrained, and to function in a relatively unplanned, spontaneous, and emotional manner (i.e., sharing news anywhere and anytime) (Lee \& Ma, 2012; Wang et al., 2015). Time constraints limit one's attention to the elements of the environment (Howard \& Sheth, 1969) and consequently lead a decision maker to choose a satisfying solution instead of an optimal one (Gao et al., 2011). Hence, when an incident occurs, information is delivered immediately on microblogs without a reduction in the timeliness of the information provided (Tobias, 2011). Such behavior is referred to as instant (real-time) information sharing (Bermingham \& Smeaton, 2010; Joly et al., 2010). Research shows that instant information sharing can change individuals' behavior and emotional states by addressing a wide variety of needs (Wang et al., 2012). Furthermore, it is extremely valuable for monitoring societal changes in contexts and mental states (Zhao \& Rosson, 2009) as information is shared and distributed across society in a timely and direct fashion (Lee \& Ma, 2012). For these reasons, microblogs have become a widely used platform for individuals to create and publish information and thoughts in real time (Oh \& Syn, 2015).

In short, instant sharing behavior is always spontaneous and reactive in nature (Bermingham \& Smeaton, 2010). This "reactiveness" is aligned with the impulsivity of human behavior, i.e., the need to express emotions predominantly precedes its 
anticipated utility (Strack et al., 2006). Therefore, instant information sharing on microblogs tends to be a stochastic behavior rather than a deterministic event (Gao et al., 2011) and, hence, can be conceptualized as a reactive and impulsive behavior (Wang et al., 2015). Based on this conceptualization, theories of impulsive behavior are appropriate in capturing and understanding the underlying mechanisms of instant information sharing in microblogs. However, prior studies have investigated information sharing primarily from the lens of reasoned action and behavioral intention, using theories such as the theory of planned behavior, motivational theory, and social exchange theory (Chai et al., 2011; Munar \& Jacobsen, 2014; Oh \& Syn, 2015). Common to these theories is the assumption of complete rationality, that is, that information sharing is primarily based on rational evaluations of the consequences of the sharing behavior. Hence, traditional theories on reasoned action may be inadequate to explain the impulsive mechanism of instant information sharing. Next, we review the literature on impulsive behavior and extend the affective response model (ARM) to develop our research model (see Figure 1).

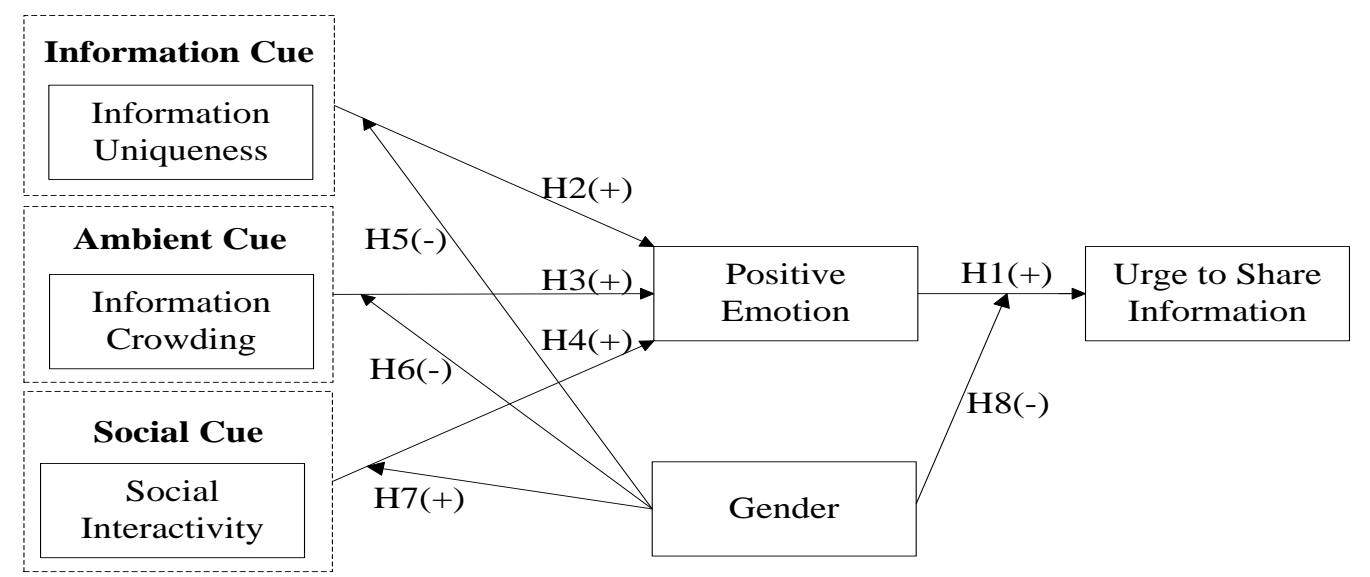

Note: A positive sign "+" (a negative sign “-”) in H5-8 indicates that the effect is stronger (weaker) for females than for males.

Fig. 1. Research model. 


\subsection{The role of urge in instant information sharing}

Broadly speaking, impulsive behavior refers to "the wish to do something elicited on a specific spot" (Strack et al., 2006, p. 206). According to this definition, one of the distinctive aspects of impulsive behavior is a sudden and spontaneous desire to act (Rook \& Hoch, 1985). This strong and spontaneous inclination is reflected by the involvement of a behavioral urge, which refers to arousing behavior with an automatic and irresistible emotional reaction to environmental cues (Kacen \& Lee, 2002).

To be more specific, the impulsive mechanism functions as "a network in which information is processed automatically through a fast and parallel spread of activation along the associative links between contents" (Strack et al., 2006, p. 208). From this perspective, a behavioral urge can be conceptualized as a proxy of impulsive behavior. Being powerful and sometimes irresistible, behavioral urges precede the immediate action and have a positive relationship with the likelihood of engaging in the impulsive behavior (Beatty \& Elizabeth Ferrell, 1998). Consistent with this perspective, the driving force of an individual's instant behavior is the high desire (i.e., urge) to act (Verplanken et al., 2005).

In contrast with intention-driven information sharing in traditional media, the preparedness of instant information sharing (i.e., the felt urge) is more likely to be spontaneous and automatic without prior consultation and evaluation (Wang et al., 2015). Given the difficulty of capturing actual information sharing behavior at the appropriate time and setting (Beatty \& Elizabeth Ferrell, 1998), we use the behavioral 
urge to share as a proxy for instant information sharing. Based on previous definitions of urge (Kacen \& Lee, 2002), we define the urge to share information as the automatic and irresistible arousal experienced by an individual to instantly share information in a microblog.

\subsection{The effect of positive emotion on the urge to share information}

Instant information sharing is often emotionally oriented (Choi \& Toma, 2014; Rosso et al., 2016; Stieglitz \& Dang-Xuan, 2013). It has been highlighted that emotions act as crucial determinants in successful and effective communication in social interactions (Cambria, 2016). That is, an important motivation of instant information sharing in microblogs is to release instantly aroused emotional responses rather than to satisfy utilitarian needs and wants (Davis \& Sajtos, 2009; Wang et al., 2013). As a result, instant information sharing behavior can cause a psychological conflict and struggle (i.e., emotion) similar to impulsive purchasing.

In a consistent manner, the psychology literature on impulsive behavior suggests that affective environmental cues primarily exert an emotional effect on the organism, who subsequently engages in the behavioral response (Eroglu et al., 2001). That is, the impact of the affective cues on response is mediated by the emotional response (Mehrabian \& Russell, 1974). Likewise, according to ARM, emotions are "induced affective states" attributed to affective cues that generate arousal and action tendencies (Zhang, 2013). From this perspective, it is the awareness of environmental cues that triggers emotional responses (Beatty \& Elizabeth Ferrell, 1998; Verhagen \& van Dolen, 2011). Under different emotional states, individuals make final decisions 
and choose their behavioral responses correspondingly, such as approach versus avoidance (Mehrabian \& Russell, 1974).

Emotional responses include both positive and negative valences. Previous research on impulsive behavior has consistently found a positive effect of positive emotion on behavioral urge (Beatty \& Elizabeth Ferrell, 1998; Hyo-Jung et al., 2011). However, prior studies have generated mixed findings regarding the effect of negative emotion on users' felt urge, which is found to be negative in some cases (Verhagen \& van Dolen, 2011) but insignificant (Beatty \& Elizabeth Ferrell, 1998) or ignored (Graa \& Dani-elKebir, 2012; Hyo-Jung et al., 2011) in other cases. Consistent with these previous findings we propose that only positive emotional experiences are associated with the behavioral urge to instantly share information on microblogs. This is mainly because instant information sharing is more likely to be an approach behavior (driven by positive emotion) than an avoidance behavior (driven by negative emotion) (Beatty \& Elizabeth Ferrell, 1998). Although both positive and negative emotions can be stimulated when sharing information, the former may be more conducive because of the sense of reward, the reduced decision complexity, and the high energy levels produced (Rook, 1987; Rook \& Gardner, 1993). Such emotional experiences are more likely to spark impulsive behavior and induce the urge to share. In contrast, users are more likely to share negative feelings to intimate friends face-to-face instead of in microblogs (i.e., easily accessible and non-intrusive media) to cheer up (Choi \& Toma, 2014). Echoing this point, previous research has found 
that negative emotion is not a major driver for the urge to update one's status in real time in microblogs (Wang et al., 2015).

Positive emotion refers to "the extent to which a person feels enthusiastic, excited, and inspired" (Verhagen \& van Dolen, 2011, p. 321). These emotional responses have been widely used as the key antecedents of impulsive behavior in previous research. For instance, it has been highlighted that impulsive behavior is a result of one's attempt to strengthen positive emotion (Mick \& DeMoss, 1990). Similar effects of emotional responses have been proposed in the context of media use, which is driven by the need to strengthen positive emotion (Katz et al., 1973).

In the context of microblogs, it has been found that Twitter is more likely to be used to share positive events (Choi \& Toma, 2014). Analogously, strengthening positive emotion has been identified as a crucial factor that influences individuals' real-time status update in microblogs (Wang et al., 2015). Thelwall et al. (2011) also found evidence that interest in events increases with strong positive sentiments. From this perspective, we infer that the urge to instantly share information is sparked by a user's desire to satisfy their positive affective needs (Katz et al., 1973). Hence, we propose the following hypothesis:

H1. Microblog users' positive emotion positively influences their urge to share information on microblogs.

\subsection{The influence of affective cues on positive emotion}

As mentioned previously, instant information sharing in social media tends to be conducted with limited cognitive capacity (Wang et al., 2015). The lack of cognitive 
evaluation and disregard for the consequences of communication readily induce individuals to be controlled by affective cues, rather than the reflective decision making process (Rosso et al., 2016; Strack et al., 2006). Importantly, it should be noted that the influence of affective dimensions (i.e., feelings and emotions) emerges not only in personal engagement (Celli et al., 2016; Rangel \& Rosso, 2016) but also in crowdsourced content (Aljanaki et al., 2016; Tobias, 2011).

Affective cues refer to those specific characteristics or features that manifest the affective quality of the stimuli (Zhang, 2013). According to ARM, affective cues "affect internal states of the individual" and can be conceptualized as "an influence that stimulates the individual" (Eroglu et al., 2001, p. 179). That is, emotional reactions are determined by affective or environmental cues that contain affective information, such as characteristics of time, product, ambient, design, and society (Graa \& Dani-elKebir, 2012; Hyo-Jung et al., 2011). Referring to these factors, we identify the affective cues that fit the context of the current study and categorize them into three types: informational (i.e., information uniqueness), ambient (i.e., information crowding), and social (i.e., social interactivity) cues. Such cues are predicted to affect users' emotional responses (i.e., positive emotion), which in turn spark the urge to share information in microblogs. The subsequent paragraphs explain our main reasons for choosing these characteristics.

\subsubsection{Information uniqueness}

Given that instant information sharing tends to be spontaneous and without a lot of reflection, the cognitive and affective forces guiding individuals' behavior are 
typically elicited at a specific time and place (Hofmann et al., 2009; Rook, 1987). That is, the information being shared is produced and delivered at a specific point in time and space (Singh et al., 2010). Following this line of reasoning, it is assumed that the input to motivate instant information sharing in microblogs is the time and location sensitivity of that information. This lens is in line with the notion of spatio-temporal granularity used to detect events in microblogs (Singh et al., 2010). Hence, information uniqueness with time and location sensitivity is proposed as an affective cue that stimulates users' instant information sharing in microblogs.

Information uniqueness not only represents the originating point of the information but also involves the specific manner in which it is presented and perceived. From this perspective, information uniqueness has been characterized as unique, original and distinguishable (Wang \& Strong, 1996). As time and location change, there will be much less, or even no use for, information seeking and sharing. One reason for this sharp drop is that the dynamic nature of the various environments makes the information less vital over time and space (Ballou \& Pazer, 1995). Correspondingly, information uniqueness increases when the information being contributed to the community is important without any redundancy and when it is likely to influence the outcome at the specific point in time and space (Ling et al., 2005).

Thus, information uniqueness is proposed as a key affective cue that may influence users' emotional response (DeLone \& McLean, 1992). This is mainly because information sharing with high uniqueness (e.g., being the first to report an 
urgent event) is normally viewed by microblog users as delivering high value to others (Wang et al., 2015). Users who have the opportunity to share such information will be more likely to experience an increase in positive emotion for being able to provide first-hand and highly valuable information to others. Thus, it has been highlighted that high uniqueness and specific goals will make individuals contribute more (Ling et al., 2005). In contrast, users' positive emotion and impulse/urge to act on the sharing behavior diminishes with time or spatial distance (Hofmann et al., 2009). Hence, we propose the following hypothesis:

H2. Microblog users' perceptions of information uniqueness positively influence their positive emotion.

\subsubsection{Information crowding}

As outsourced real-time platforms, microblogs create real-time scenarios and provide situational awareness through users' instant information sharing (Tobias, 2011). In other words, a great deal of user-generated content produces real-time maps of when an incident occurs and allows for real-time sensing of the world (Bermingham \& Smeaton, 2010). Previous studies have suggested that perceived crowding (i.e., the perception of environment density and personal sensation (Stokols, 1972)) acts as a key ambient characteristic that influences impulsive behavior (Graa \& Dani-elKebir, 2012; Hyo-Jung et al., 2011). Consistent with this viewpoint, we propose that perceived information crowding (i.e., a large amount of information being generated, exchanged, and shared in the microblog by a crowd of users when an 
incident occurs (Bermingham \& Smeaton, 2010; Demirbas et al., 2010)) will affect users' emotions and behavioral urge.

According to the crowd psychology literature, individuals in a crowd allow their behavior and emotions to be affected by people in their surroundings with which they share similar emotional experiences (Glynn et al., 1999). Extending this point into the current context of instant information sharing, perceived information crowding will inform users' thoughts and behavior, causing them to be influenced by the crowd in the microblog community. That is, individuals tend to have the same emotions and engage in similar behavior as the crowd. This is mainly because information crowding in microblogs increases the tendency to approach and participate through user-consensus (Tobias, 2011), thus acting as a positive (rather than negative) subjective experience and facilitating the desired behavior (i.e., instant information sharing) (Hui \& Bateson, 1991). Hence, we believe that information crowding will positively influence individuals' positive emotion and eventually their instant information sharing behavior. We propose the following hypothesis:

H3. Microblog users' perceptions of information crowding positively influence their positive emotion.

\subsubsection{Social interactivity}

Microblogs provide the critical functions of facilitating users' timely communication and social value (Zhao \& Lu, 2012). This pattern of social interaction has been identified as a crucial determinant of impulsive behavior (Graa \& Dani-elKebir, 2012; Hyo-Jung et al., 2011). In line with this finding, we propose that 
interactivity in a microblog setting has a bearing on users' emotions and behavioral urges. Given that we are investigating the social characteristics of instant information sharing, we focus on human-human interactions (i.e., interpersonal communication between users), rather than the interactivity between users and the system. From this perspective, interactivity is defined as "the degree to which two or more communication parties can act on each other" in a microblog (Liu \& Shrum, 2002, p. 54).

Microblogs are primarily designed for user-to-user interactivity (Zhao \& Lu, 2012). They allow users to easily communicate with others via interacting functions such as commenting, replying, retweeting, and following (Hsi-Peng et al., 2010). The human-human interaction thus produces great user values, positive attitudes, and satisfaction (Hsi-Peng et al., 2010; Lee \& Cho, 2011; Zhao \& Lu, 2012), contributes to seeking positive evaluations, and leads to the avoidance of criticism from others (Park \&Chung, 2011). The social values and communication benefits yielded from interactivity cause users to experience positive emotional changes and promote their instant information sharing behavior on microblogs. To some extent, social interactivity serves as the underlying basis of information creating and sharing (Hsi-Peng et al., 2010). Consistent with this point, network structures with high interactivity have been found to play a crucial role in the dynamics of information flow, and consequently promote information sharing within a microblog (Hsi-Peng et al., 2010). Hence, we propose the following hypothesis: 
H4. Microblog users' perceptions of interactivity positively influence their positive emotion.

\subsection{The moderating role of gender in instant information sharing}

According to the social role theory (SRT), the difference in social behavior between genders stem from the socialization process (i.e., societal and cultural expectations) (Eagly, 1987). A fundamental assumption of SRT is that males are characterized as more agentic (i.e., masterful, instrumental, and competitive) and females are characterized as more communal (i.e., friendly, cooperative, and emotionally expressive) (Archer, 1996). In other words, men focus largely on outcome, whereas women focus more on interpersonal relationships (Chai et al., 2011).

Based on this line of reasoning, prior research has indicated that gender differences play a key role in information sharing behavior, such that men prefer to use knowledge management systems, whereas women are more likely to use socialization and interpersonal strategies (Taylor, 2004). Similarly, in computer-mediated communications, males tend to get and give information whereas females tend to post and understand information ( $\mathrm{Lu} \&$ Hsiao, 2009). Extending this to the microblog context, the effect of commitment on consumer participation in enterprise microblogging has been demonstrated to be stronger for females, whereas trust has a stronger effect on commitment and participation for males (Zhang et al., 2015). Taken together, this line of literature suggests that women are more interested in the interpersonal communication of information sharing, whereas men are more 
interested in the informative and functional aspects of this behavior (Weiser, 2000).

While these findings provide a useful insight in understanding users' information sharing behavior as a reasoned action, instant information sharing tends to be more impulsive and less deliberate (Wang et al., 2015). Therefore, the relative influence of affective cues on emotions and urges might be different due to this changed usage setting. In this case, we should adapt previous propositions about the role of gender to the instant information sharing context with caution.

Due to the agentic nature of males and their "instrumental and competitiveness component", we propose that informational (e.g., more instrumental) and ambient (e.g., more competitive) cues have a deeper impact on positive emotions in males. On the contrary, social cues (e.g., more interpersonal) have a more meaningful effect on positive emotion in females. In line with this assumption, prior research has found that men tend to focus more on information and opinion, whereas women are more interested in social interactions when using blogs (Pedersen \& Macafee, 2007). Hence, three further hypotheses are proposed as follows:

H5. The effect of information uniqueness on positive emotion is greater for males than for females.

H6. The effect of information crowding on positive emotion is greater for males than for females.

H7. The effect of social interactivity on positive emotion is greater for females than for males.

Furthermore, based on the psychology and neurology literature, gender 
differences exist because of the development of organizing factors at critical phases, such that hormones play a permanent role in influencing the vulnerability of impulsive behavior (Weafer \& de Wit, 2014). Specifically, it has been suggested that males are more likely to engage in impulsive behavior than females, albeit with a difference depending on the task and subject (Weafer \& de Wit, 2014). Consistently, scholars have found that, compared to women, men show greater sensation seeking tendencies (Cross et al., 2011). Extending this finding to the context of the current study, we hypothesize that when experiencing positive emotion, men are more likely than women to have the urge to instantly share information on microblogs.

H8. The effect of positive emotion on the urge to share information is greater for males than for females.

\section{Methodology}

To test the proposed research model, an online survey of microblog users was conducted in China, which has the largest population of microblog users in the world. We chose Sina Weibo (http://www.weibo.com) as the research site of this study, because (1) it is the most popular microblog service and the largest social platform in China, and (2) users are highly encouraged to share information instantly on Sina Weibo by posting graphical and emotional content with images, music, and video files attached.

\subsection{Measurement}

As shown in Appendix A, the majority of the constructs were measured using multiple items adapted from previous studies, using a seven-point scale ranging from 
1 (strongly disagree) to 7 (strongly agree). The measures for urge to share information and positive emotion were adapted from Beatty and Elizabeth Ferrell (1998), information uniqueness from Wang and Strong (1996), and social interactivity from McMillan and Hwang (2002). The scales for information crowding were developed on the basis of its definition and existing scales on perceived crowding (Hui \& Bateson, 1991; Machleit et al., 2000).

\subsection{Data collection}

The survey was conducted in early April, 2014. Two well-trained post-graduate students were recruited to independently send invitation messages with a link to the online questionnaire to microblog users. A total of 550 active users who had ever posted information in trending topics in microblogs received this private invitation. Incentives (i.e., a phone card valued at RMB30) were provided to encourage participation in the survey. The data collection lasted for one month and ended when no new responses were being generated.

To select eligible respondents for the survey, we used the following selection criteria. At the beginning of the survey, we first provided the definition and examples of instant information sharing, and required respondents to indicate whether they had ever shared instant information on Sina Weibo. If they answered yes, the respondents were further asked to recall the last time they instantly shared information and answer relevant questions. We also collected their demographic information (i.e., age, gender, and education) and their usage experience (i.e., length and frequency of usage). In this way, we were able to target the expected population of microblog users. 
In total, 341 microblog users responded to the online questionnaire for a response rate of 62 percent. After screening for invalid responses (e.g., retweeting rather than tweeting), 34 questionnaires were excluded and 307 valid responses were processed for further analysis. To test the non-response bias, T-tests of each item were conducted between the first and last 50 respondents. The results indicated no significant difference between the two groups ( $p>0.10$ in all cases), demonstrating no serious concern about non-response bias in this study (Armstrong \& Overton, 1977). Table 1 shows the respondents' profile, which is quite similar to the microblog user profiles in China reported in prior studies (Wang et al., 2015; Zhao \& Lu, 2012).

\section{Table 1}

Respondents' profile.

\begin{tabular}{llll}
\hline Characteristic & & Distribution & Percentage \\
\hline Gender & Female & 181 & $58.96 \%$ \\
Age & Male & 126 & $41.04 \%$ \\
Education & $12-20$ & 99 & $32.25 \%$ \\
& $21-30$ & 208 & $67.75 \%$ \\
& Junior high school & 4 & $1.30 \%$ \\
Length of usage & Senior high school & 6 & $1.95 \%$ \\
& Undergraduate & 201 & $65.48 \%$ \\
& Postgraduate & 96 & $31.27 \%$ \\
& Below 1 month & 8 & $2.60 \%$ \\
& Under 3 months & 26 & $8.47 \%$ \\
Frequency of usage & Between 3 and 6 months & 47 & $15.31 \%$ \\
& Between 6 and 12 months & 69 & $22.48 \%$ \\
& Above 12 months & 157 & $51.14 \%$ \\
& Less than once a month & 7 & $2.28 \%$ \\
& Once a month & 22 & $7.17 \%$ \\
& Once a week & 52 & $16.94 \%$ \\
& Several (<7) times a week & 79 & $25.73 \%$ \\
& Once a day & 59 & $19.22 \%$ \\
& Several times a day & 88 & $28.66 \%$ \\
\hline
\end{tabular}




\section{Data analysis and results}

LISREL 8.70 was used to analyze the data. We chose LISREL, one of the most widely used structural equation modeling techniques in the IS field, because of its appropriateness for strongly theory-based, confirmatory research (Gefen et al., 2011). Following the two-step analytical procedure, we first assessed the measurement model and then evaluated the structural model (Hair et al., 2006).

\subsection{Measurement model}

Confirmatory factor analyses were performed to assess the psychometric properties of the measurement model for the whole sample and for the two subsamples (i.e., males vs. females). As expected, and as shown in Table 2, the composite reliability (CR) and the average variance extracted (AVE) of each construct exceeded 0.70 and 0.50 respectively, demonstrating good convergent validity (Fornell \& Larcker, 1981). Furthermore, the square root of AVE for each construct was greater than the correlations between the specific construct and other constructs (see Table 3), thereby supporting high discriminant validity (Fornell \& Larcker, 1981).

The measurement model fit was evaluated by using multiple fitness indices. Table 4 shows the $\chi^{2} /$ degrees of freedom (df), goodness-of-fit index (GFI), adjusted goodness-of-fit index (AGFI), comparative fit index (CFI), normed fit index (NFI), non-normed fit index (NNFI), and root mean square error of approximation (RMSEA). All statistics satisfied the acceptable ranges, indicating a good fit of the measurement model (Bentler \& Bonett, 1980; Segars \& Grover, 1993). 
Table 2

Results of the confirmatory factor analysis.

\begin{tabular}{|c|c|c|c|c|c|c|c|c|c|c|}
\hline \multirow[t]{2}{*}{ Construct } & \multirow[t]{2}{*}{ Item } & \multicolumn{3}{|c|}{ Full sample } & \multicolumn{3}{|c|}{ Female subgroup } & \multicolumn{3}{|c|}{ Male subgroup } \\
\hline & & Loadings & $\mathrm{CR}$ & AVE & Loadings & $\mathrm{CR}$ & AVE & Loadings & $\mathrm{CR}$ & AVE \\
\hline \multirow{3}{*}{$\begin{array}{l}\text { Information } \\
\text { uniqueness } \\
\text { (IU) }\end{array}$} & IU1 & 0.73 & 0.80 & 0.57 & 0.73 & 0.82 & 0.61 & 0.76 & $0 . .78$ & 0.54 \\
\hline & IU2 & 0.83 & & & 0.90 & & & 0.75 & & \\
\hline & IU3 & 0.69 & & & 0.69 & & & 0.69 & & \\
\hline \multirow{4}{*}{$\begin{array}{l}\text { Information } \\
\text { crowding } \\
\text { (IC) }\end{array}$} & IC1 & 0.86 & 0.89 & 0.68 & 0.84 & 0.89 & 0.67 & 0.88 & 0.90 & 0.69 \\
\hline & IC2 & 0.87 & & & 0.87 & & & 0.88 & & \\
\hline & IC3 & 0.82 & & & 0.85 & & & 0.79 & & \\
\hline & IC4 & 0.73 & & & 0.71 & & & 0.76 & & \\
\hline \multirow{4}{*}{$\begin{array}{l}\text { Social } \\
\text { interactivity } \\
\text { (SI) }\end{array}$} & SI1 & 0.77 & 0.88 & 0.64 & 0.80 & 0.91 & 0.71 & 0.74 & 0.83 & 0.55 \\
\hline & SI2 & 0.79 & & & 0.83 & & & 0.75 & & \\
\hline & SI3 & 0.84 & & & 0.88 & & & 0.78 & & \\
\hline & SI4 & 0.79 & & & 0.86 & & & 0.69 & & \\
\hline \multirow{4}{*}{$\begin{array}{l}\text { Positive } \\
\text { emotion } \\
(\mathrm{PE})\end{array}$} & PE1 & 0.85 & 0.92 & 0.75 & 0.86 & 0.91 & 0.72 & 0.83 & 0.93 & 0.78 \\
\hline & PE2 & 0.95 & & & 0.94 & & & 0.96 & & \\
\hline & PE3 & 0.88 & & & 0.84 & & & 0.92 & & \\
\hline & PE4 & 0.77 & & & 0.73 & & & 0.81 & & \\
\hline \multirow{3}{*}{$\begin{array}{l}\text { Urge to } \\
\text { share } \\
\text { information } \\
\text { (USI) }\end{array}$} & USI1 & 0.80 & 0.83 & 0.63 & 0.79 & 0.86 & 0.67 & 0.84 & 0.79 & 0.56 \\
\hline & USI2 & 0.85 & & & 0.89 & & & 0.75 & & \\
\hline & USI3 & 0.72 & & & 0.78 & & & 0.64 & & \\
\hline
\end{tabular}

Table 3

Inter-construct correlations and square roots of AVE.

\begin{tabular}{llllll}
\hline & IU & IC & SI & PE & USI \\
\hline Full & & & & & \\
IU & $0.76^{a}$ & & & & \\
IC & 0.19 & 0.82 & 0.80 & & \\
SI & 0.26 & 0.59 & 0.39 & 0.87 & \\
PE & 0.34 & 0.34 & 0.38 & 0.42 & \\
USI & 0.31 & 0.39 & 0.79 \\
& & & & & \\
Female & & & & & \\
IU & 0.78 & 0.82 & & 0.85 \\
IC & 0.15 & 0.63 & 0.84 & & \\
SI & 0.20 & 0.30 & 0.43 & 0.85 & \\
PE & 0.23 & 0.37 & 0.44 & & \\
USI & 0.27 & & & & \\
& & & & & \\
Male & & 0.83 & & & \\
IU & 0.74 & & & & \\
IC & 0.22 & 0.83 & & \\
\hline
\end{tabular}




\begin{tabular}{llllll}
\hline SI & 0.35 & 0.52 & 0.74 & & \\
PE & 0.48 & 0.39 & 0.35 & 0.88 & \\
USI & 0.38 & 0.41 & 0.31 & 0.57 & 0.75 \\
\hline
\end{tabular}

Note: The diagonal elements are the square roots of the AVE extracted from each construct.

Table 4

Fit indices of the measurement model and structural model.

\begin{tabular}{|c|c|c|c|c|c|c|c|}
\hline Fit index & $\begin{array}{l}\text { Full } \\
\text { MM }\end{array}$ & $\begin{array}{l}\text { Full } \\
\text { SM }\end{array}$ & $\begin{array}{l}\text { Female } \\
\text { MM }\end{array}$ & $\begin{array}{l}\text { Female } \\
\text { SM }\end{array}$ & $\begin{array}{l}\text { Male } \\
\text { MM }\end{array}$ & $\begin{array}{l}\text { Male } \\
\text { SM }\end{array}$ & $\begin{array}{l}\text { Recommended } \\
\text { criteria }\end{array}$ \\
\hline$\chi 2 / \mathrm{df}$ & 1.98 & 2.25 & 1.92 & 2.13 & 1.64 & 1.67 & $<3.00$ \\
\hline GFI & 0.92 & 0.91 & 0.87 & 0.86 & 0.85 & 0.84 & $\geqq 0.80$ \\
\hline AGFI & 0.89 & 0.87 & 0.82 & 0.81 & 0.80 & 0.80 & $\geqq 0.80$ \\
\hline CFI & 0.98 & 0.97 & 0.96 & 0.96 & 0.97 & 0.96 & $\geqq 0.90$ \\
\hline NFI & 0.96 & 0.96 & 0.94 & 0.93 & 0.92 & 0.92 & $\geqq 0.90$ \\
\hline NNFI & 0.98 & 0.97 & 0.95 & 0.95 & 0.96 & 0.96 & $\geqq 0.90$ \\
\hline RMSEA & 0.057 & 0.064 & 0.071 & 0.079 & 0.072 & 0.073 & $\leqq 0.08$ \\
\hline
\end{tabular}

Note: MM-measurement model; SM-structural model.

Common method bias was tested using two methods. First, Harman's single factor test indicated that no single factor accounted for the majority of the covariance, suggesting no serious threat (Podsakoff et al., 2003). Second, a latent common method variance (CMV) factor was included in the model to allow all the items to be loaded on it. The structural model was examined both with and without the latent CMV factor. The results showed that the CMV-based variance is very small and much smaller than the construct-based variance, suggesting that the common method bias was unlikely to be a concern in this study (Ayyagari et al., 2011; Podsakoff et al., 2003).

\subsection{Structural model}


Figure 2 shows the results of the model test, including the variance explained and path coefficients. An adequate amount (26 percent) of the variance in instant information sharing is explained by the proposed model. The model supports H1, meaning that positive emotion $(\beta=0.51, t=7.91)$ significantly influences the urge to share information. As for the antecedents of positive emotion, both information uniqueness $(\beta=0.26, t=4.15)$ and social interactivity $(\beta=0.29, t=3.37)$ have significant effects on positive emotions, and thus $\mathrm{H} 2$ and $\mathrm{H} 4$ are supported. However, the effect of perceived information crowding on positive emotions is insignificant $(\beta=0.13$, $\mathrm{t}=1.54$, and thus $\mathrm{H} 3$ is not supported). Overall, a significant amount (28\%) of variation in positive emotion is explained by the three affective cues (i.e., information uniqueness, information crowding, and social interactivity).

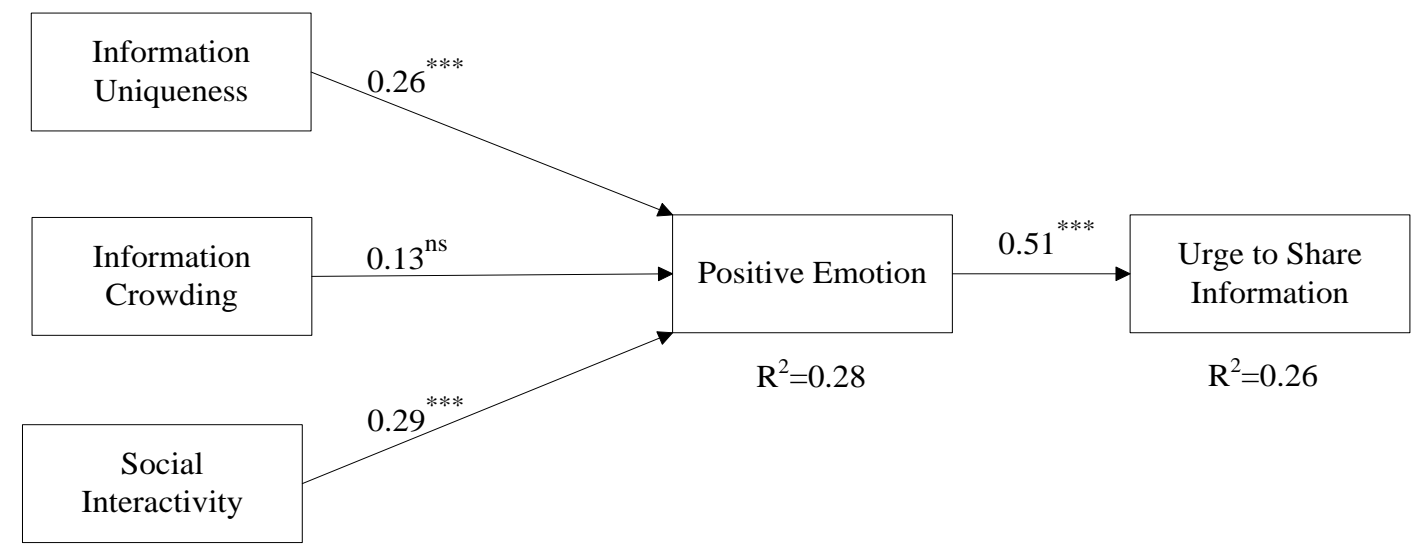

Fig. 2. Structural model assessment. Note: $* * * p<0.001$; ns-non-significant.

We also conducted a between-group analysis to test the moderating role of gender (see Table 5). To investigate gender differences, we followed the procedure proposed by Keil et al. (2000) to compare the coefficient differences of the corresponding structural paths for the two sub-samples (i.e., females vs. males). The results indicated that the effects of information uniqueness $\left(t_{\text {spooled }}=-28.591\right.$, female path coeff. $=0.14$, 
male path coeff. $=0.45)$ and information crowding $(\mathrm{t}$ spooled $=-18.872$, female path coeff. $=-0.01$, male path coeff. $=0.24)$ on positive emotion were significantly stronger for males than females, supporting H5 and H6. As expected, the effects of social interactivity $\left(\mathrm{t}_{\text {spooled }}=27.764\right.$, female path coeff. $=0.47$, male path coeff. $=$ 0.07) on positive emotions were found to be greater for females than males, supporting H7. In addition, the results suggested that positive emotions $\left(\mathrm{t}_{\text {spooled }}=\right.$ -22.354 , female path coeff. $=0.43$, male path coeff. $=0.66)$ exert a greater effect on the urge to share for males than females, supporting H8. The results of the subgroup analysis for females and males are shown in Fig. 3a and 3b, respectively.

\section{Table 5}

Path comparisons: Females $\left(\mathrm{N}_{1}=181\right)$ vs. males $\left(\mathrm{N}_{2}=126\right)$.

\begin{tabular}{|c|c|c|c|c|}
\hline \multirow[t]{2}{*}{ Paths } & \multicolumn{2}{|c|}{ Path coefficients } & \multirow[t]{2}{*}{$\mathrm{t}_{\text {spooled }}$} & \multirow{2}{*}{$\begin{array}{l}\text { Hypothesis } \\
\text { support }\end{array}$} \\
\hline & Female $\left(\mathrm{N}_{1}=181\right)$ & Male $\left(\mathrm{N}_{2}=126\right)$ & & \\
\hline $\begin{array}{l}\text { H5: Information } \\
\text { uniqueness } \rightarrow \\
\text { positive emotion }\end{array}$ & $0.14(0.08)^{\mathrm{ns}}$ & $0.45(0.11)^{* * * * *}$ & $-28.591^{* * * *}$ & Supported \\
\hline $\begin{array}{l}\text { H6: Information } \\
\text { crowding } \rightarrow \\
\text { positive emotion }\end{array}$ & $-0.01(0.11)^{\mathrm{ns}}$ & $0.24(0.12)^{*}$ & $-18.872^{* * *}$ & Supported \\
\hline $\begin{array}{l}\text { H7: Social } \\
\text { interactivity } \rightarrow \\
\text { positive emotion }\end{array}$ & $0.47(0.12)^{* * *}$ & $0.07(0.13)^{\mathrm{ns}}$ & $27.764^{* * * *}$ & Supported \\
\hline $\begin{array}{l}\text { H8: Positive } \\
\text { emotion } \rightarrow \text { urge to } \\
\text { share information }\end{array}$ & $0.43(0.08)^{* * *}$ & $0.66(0.10)^{* * *}$ & $-22.354^{* * *}$ & Supported \\
\hline
\end{tabular}

Note. $* p<0.05 ; * * * p<0.001 ;$ ns - non-significant. 


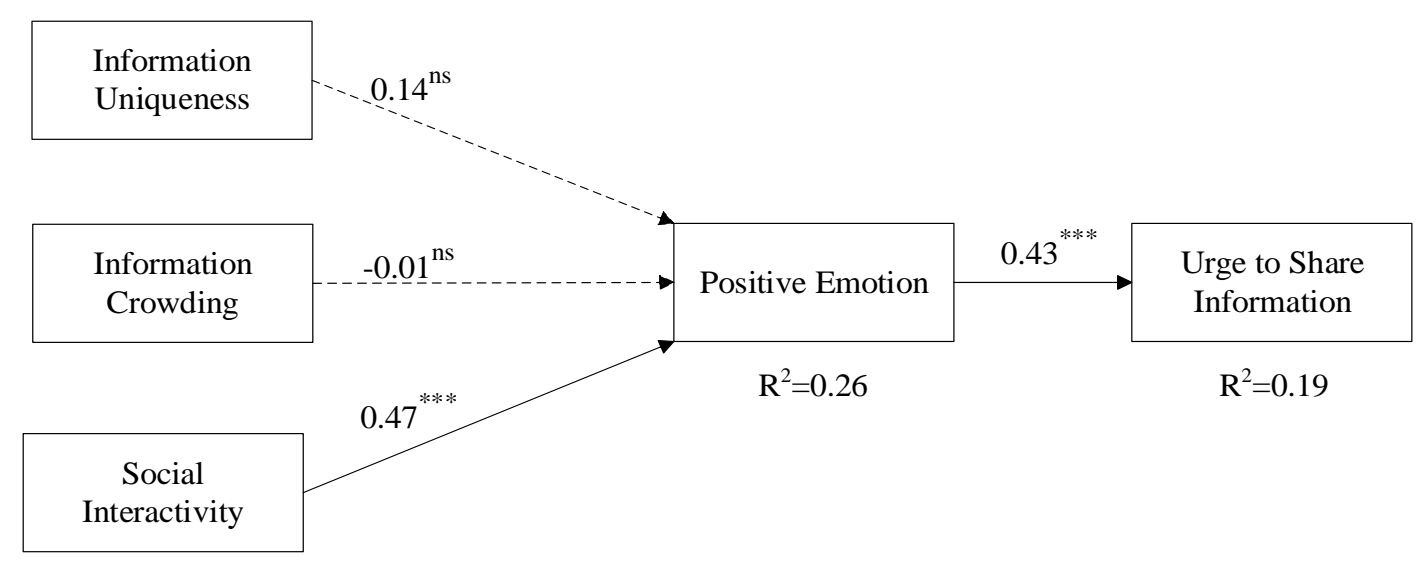

Fig. 3a. Path estimates of LISREL analysis for the female sample $\left(\mathrm{N}_{1}=181\right)$.

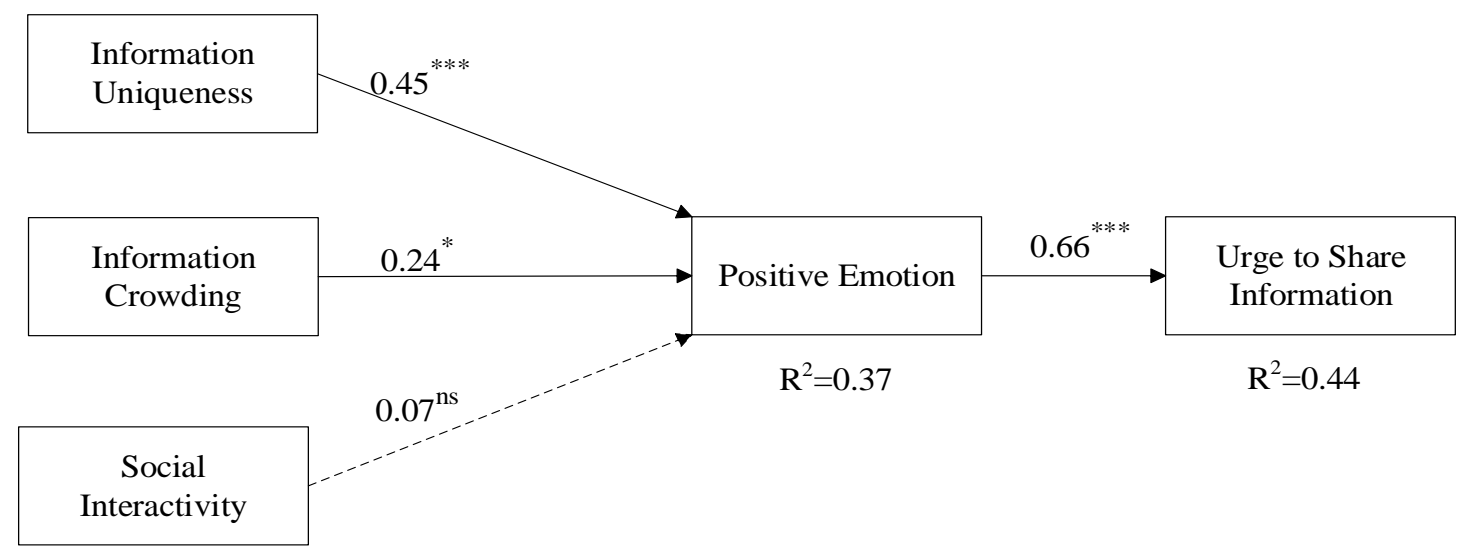

Fig. 3b. Path estimate of LISREL analysis for the male sample $\left(\mathrm{N}_{2}=126\right)$.

\section{Discussion}

\subsection{Key findings}

This study examines the effects of informational (i.e., information uniqueness), ambient (i.e., information crowding), and social (i.e., social interactivity) cues on positive emotion, which in turn predicts users' urge to share information on microblogs, as well as the moderating effects of gender on these relationships. The outcome is a rich set of interesting findings.

Specifically, consistent with previous research, positive emotion is found to be a crucial enabler of the urge to instantly share information on microblogs (Wang et al., 
2015). This finding provides evidence for our proposition that instant information sharing is more impulsive and emotional in nature in comparison to traditional information sharing. In terms of its antecedents, information uniqueness and social interactivity are relatively balanced in influencing positive emotions, albeit with social interactivity perhaps exerting a stronger effect.

Unexpectedly, the relationship between information crowding and positive emotion is insignificant. We thus conducted a post hoc mediation test using Baron and Kenny's method (Baron \& Kenny, 1986). The results indicated that information crowding was significantly associated with the urge to share, suggesting that the felt urge can be directly affected by information crowding, bypassing the emotional response (see Appendix B). A plausible explanation of this finding is that in the context of social media, instant information sharing is vulnerably affected by perceived crowding and is more likely performed in a spontaneous and unplanned way than in traditional media (e.g., weblogs, discussion forums).

Moreover, the empirical findings provide support for the notion that gender differences exist in the way various affective cues influence positive emotions and the effects of positive emotion on the urge to share. Although instant information sharing on microblogs is a largely impulsive behavior sparked by multiple cues, the strengths of these affective cues are not equal in male and female users. Just as expected, the results indicate that: (1) men are more sensitive to environmental cues with specific, unique, and distinguishable values; (2) men are more likely to participate in the community and share information when there is crowding; (3) men are more likely 
than women to experience positive emotions and engage in impulsive information sharing; and (4) women put more value on establishing and maintaining their interpersonal relationships on microblogs. These findings offer important theoretical and practical implications.

\subsection{Theoretical implications}

This study provides a number of contributions to research. First, while existing research has pervasively investigated information sharing in various platforms, little (if any) research has been devoted to understanding instant information sharing on microblogs. With the goal of filling that research gap, the current study identifies the characteristics of instant information sharing on microblogs (e.g., time constraints, limited cognitive capacity, and emotional orientation), and thus contributes to conceptualizing instant information sharing in the IS research. This exploration has advanced research in this field by establishing a general understanding of instant information sharing on microblogs, opening a new avenue for future research.

Second, while prior research on information sharing has mostly taken a reflective (i.e., reasoned-action) view, the current study theorizes instant information sharing on microblogs from the perspective of impulsive behavior. To advance our current understanding of information sharing, we propose that instant information sharing on microblogs is an impulsive behavior driven by affective cues. Extending the impulsive behavior literature, we develop and validate a research model to investigate the effects of three affective cues - informational, ambient, and social cues - on individuals' positive emotions, which in turn affect the urge to share. We extend the 
theories of impulsive behavior, especially regarding the roles and antecedents of felt urge (Beatty \& Elizabeth Ferrell, 1998; Verhagen \& van Dolen, 2011), into a new context, namely, instant information sharing on microblogs. Hence, our study contributes to the IS literature by adapting the urge-based view to understand instant information sharing on microblogs, and providing an enriched explanation of the unreflective information sharing domain.

Third, we contribute by extending the research on the social role of gender in the context of instant information sharing. Consistent with prior research on gender differences in information sharing (Chai et al., 2011; Taylor, 2004), our findings suggest that men are more pragmatic, instrumental, independent, and task-oriented, even when engaging in more impulsive behavior. As such, men are more likely to be influenced by informational and ambient cues, such that a high level of information uniqueness and perceived information crowding will significantly influence their positive emotion. In contrast, women are more socially oriented when it comes to instant information sharing, echoing their interdependent and interpersonal characteristics (Eagly, 1987).

Furthermore, we offer insights into understanding gender differences from an impulsive behavioral perspective. Contrary to the traditional view of females' emotional orientation, males are more likely to feel the urge to share when experiencing positive emotions, thus showing more impulsivity in instant information sharing on microblogs than females (Cross et al., 2011; Weafer \& de Wit, 2014). In sum, gender plays a contingent role in influencing individuals' instant information 
sharing behavior. This moderating role of gender provides insights into understanding and explaining individuals' impulsive behavior.

\subsection{Practical implications}

This study has important managerial implications for at least two sets of practitioners. First, it offers insights for microblog service providers in how to motivate their users to contribute information instantly. Prior research has suggested that community success largely depends on "making useful, timely, and helpful information available to the community" (McLureet al., 2000, p. 170); the lack of real-time information can inhibit the long-term sustainability of virtual communities (Ling et al., 2005). Given the significance of instant information sharing, it is important for microblog service providers to understand why individuals share instant information with others and how to encourage impulsive sharing. The model developed in the current study provides useful insights on this subject. Specifically, to promote users' urge to share information, microblog service providers could arouse their positive emotions by strengthening the associated enablers. For instance, they could (1) encourage users' original information sharing by adding specific marks; (2) increase information crowding by showing the total number of tweets; and/or (3) enhance social interactivity by improving reciprocal relationships among users. In addition, an automatic tool capable of mining real-time sentiments would be extremely useful, not only for commercial purposes but also for monitoring intelligence in the diffusion of cyber-information (Cambria et al., 2016). 
Second, as microblogs have become a platform for promoting brands and for word-of-mouth advertising, corporations and institutions have been paying attention to users' information seeking and sharing behavior on microblogs. It has been found that social media technology usage contributes to social customer relationship management (Trainor et al., 2014). Social media marketing activities also positively influence customer equity (including value equity, relationship equity, and brand equity) (Kim \& Ko, 2012). Furthermore, empirical research has found that user-generated content in social media influences consumer purchasing behavior (Goh et al., 2013). Thus, understanding the mechanisms for individuals' urge to share information instantly is very important for these organizations to develop effective systems to motivate more instant information sharing on microblogs. However, it should be noted that there are gender differences in individuals' emotional and behavioral responses. In general, our results suggest that marketers should develop different strategies for male and female users to stimulate their urge to share. Highlighting informational cues and incorporating a great mass of ambient cues is likely to be an effective strategy for males, but may be insufficient for female users who put a much higher emphasis on social cues. Rather, to spark female users' positive emotion, marketers should focus more on interpersonal relationships and highlight the social interactivity in the process of instant information sharing. For that matter, operators could utilize and expand social interactivity through various means, such as (1) encouraging direct tweets signaled by an @ symbol (Huberman et al., 2009); (2) conceptualizing an imagined audience evoked through tweets (Marwick \& 
Boyd, 2011); (3) improving the real-time feedback mechanism in conversations (Boyd et al., 2010); and (4) enhancing the notification system by adding more visualizations. Such illustrations and clarifications of the underlying process of individuals' instant information sharing would be significantly beneficial for practitioners.

\subsection{Limitations and future research direction}

The current study is not without limitations, suggesting directions for future research. First, although the three types of affective cues (e.g., information uniqueness, perceived crowding, and social interactivity) proposed in our model account for a sizeable amount of variance in the dependent variable, other types of cues (e.g., IT facilitator) may also play roles in influencing users' instant information sharing on microblogs. Future research could extend the current study by investigating other cues related to information sharing behavior and, possibly, comparing their relative importance.

Second, despite being influenced by affective cues, impulsive behavior is also potentially influenced by individual personalities (Hyo-Jung et al., 2011). Future researchers should consider personal characteristics to investigate their effects on instant information sharing.

Third, this study theorizes that instant information sharing on microblogs is an impulsive behavior, rather than reasoned action. Nevertheless, behavior can be a 
result of both impulsive and reflective mechanisms enabled by personal and situational characteristics (Strack et al., 2006). Future researchers could investigate how the reflective and impulsive mechanisms interact at various stages of information processing to provide deeper insights for designers and managers to enable them to build and maintain vibrant microblogs.

\section{Conclusion}

This study illustrates the factors and mechanisms that drive users' urge to instantly share information on microblogs. Specifically, we use an impulsive behavior lens to understand that instant information sharing, which differentiates our study from many previous efforts that adopt reflective perspectives to investigate information sharing in traditional virtual communities. We also demonstrate the moderating role of gender in users' instant information sharing. The empirical findings indicate that informational (i.e., information uniqueness), ambient (i.e., information crowding), and social (i.e., social interactivity) cues arouse individuals' positive emotion, which subsequently promote their urge to share information. In particular, males are more likely to be stimulated by informational and ambient cues, whereas social cues play a more dominant role in female users. This study complements the existing literature on information sharing as a reasoned action by opening up a new avenue for future research on instant information sharing as an impulsive behavior, and provides rich insights for practitioners. 


\section{Acknowledgement}

The work described in this article was supported by grants from National Science Foundation of China (Project No. 71202034; Project No. 71201096; Project No. $71601080)$

\section{Appendix A. Measurement Scales}

Information uniqueness adapted from Wang and Strong (1996)

1. I think that the information I have shared on Sina Weibo has been distinguishable.

2. I think that the information I have shared on Sina Weibo has been unique.

3. I think that the information I have shared on Sina Weibo has been original.

Information crowding self-developed on the basis of Tobias (2011)

1. A great deal of information was reported on Sina Weibo about that incident.

2. Large pieces of information were posted on Sina Weibo when that incident occurred.

3. There was a lot of information generated by users on Sina Weibo about that topic.

4. Crowded information was shared on Sina Weibo on that theme.

Social interactivity adapted from McMillan and Hwang (2002)

1. Two-way communication was enabled on Sina Weibo.

2. Concurrent communication was enabled on Sina Weibo.

3. Sina Weibo was interpersonal. 
4. Conversation was enabled on Sina Weibo.

Positive emotion adapted from Beatty and Elizabeth Ferrell (1998)

1. When sharing that information on Sina Weibo, I was excited.

2. When sharing that information on Sina Weibo, I was enthusiastic.

3. When sharing that information on Sina Weibo, I was proud.

4. When sharing that information on Sina Weibo, I was inspired.

Urge to share information adapted from Beatty and Elizabeth Ferrell (1998)

1. I experienced a number of sudden urges to share that information on Sina Weibo.

2. I felt a sudden urge to share that information on Sina Weibo.

3. Even though it was not planned, I really wanted to share that information on Sina Weibo.

\section{Appendix B. Mediation Test}

To test the potential mediating effects of positive emotion in the relationship between environmental cues (i.e., information, ambient, and social cues) and the felt urge, we used Baron and Kenny's method (Baron \& Kenny, 1986). As summarized in Table B1, positive emotion fully mediated the effect of social interactivity and partially mediated the effect of information uniqueness on the urge to share.

\section{Table B1}

The mediation effect test.

\begin{tabular}{|c|c|c|c|c|c|c|c|}
\hline \multicolumn{3}{|c|}{ Constructs } & \multicolumn{4}{|c|}{ Path coefficient } & \multirow[t]{3}{*}{ Mediation existence } \\
\hline IV & MV & DV & $\mathrm{IV} \rightarrow \mathrm{DV}$ & $\mathrm{IV} \rightarrow \mathrm{M}$ & \multicolumn{2}{|c|}{$\mathrm{IV}+\mathrm{M} \rightarrow \mathrm{DV}$} & \\
\hline & & & & & $\mathrm{IV} \rightarrow \mathrm{DV}$ & $\mathrm{M} \rightarrow \mathrm{DV}$ & \\
\hline IU & PE & USI & $0.25^{* * *}$ & 0.25 & $0.19 *$ & $0.27^{* * * *}$ & Partial \\
\hline IC & PE & USI & 0.24 & $0.12^{\mathrm{ns}}$ & $0.21^{*}$ & 0.27 *** & None \\
\hline SI & PE & USI & 0.25 & 0.29 & $0.17^{\mathrm{nS}}$ & 0.27 & Full \\
\hline
\end{tabular}


Notes. IV: independent variable; MV: mediator variable; DV: dependent variable; IU: information uniqueness; IC: information crowding; SI: social interactivity; PE: positive emotion; USI: urge to share information. ${ }^{*} p<0.05 ;{ }^{* *} p<0.01 ;{ }^{* * *} p<0.001$. 


\section{References}

Aljanaki, A., Wiering, F., \& Veltkamp, R. C. (2016). Studying emotion induced by music through a crowdsourcing game. Information Processing \& Management, 52(1), 115-128.

Armstrong, J.S. \& Overton, T.S. (1977). Estimating nonresponse bias in mail surveys. Journal of Marketing Research, 14 (3), 396-402.

Archer, J. (1996). Sex differences in social behavior: Are the social role and evolutionary explanations compatible? American Psychologist, 51(9), 909-917.

Ballou, D. P., \& Pazer, H. L. (1995). Designing information systems to optimize the accuracy-timeliness tradeoff. Information Systems Research, 6(1), 51-72.

Baron, R. M., \& Kenny, D. A. (1986). The moderator-mediator variable distinction in social psychological research: Conceptual, strategic, and statistical considerations. Journal of Personality and Social Psychology, 51(6), 1173-1182.

Beatty, S. E., \& Elizabeth Ferrell, M. (1998). Impulse buying: Modeling its precursors. Journal of Retailing, 74(2), 169-191.

Bentler, P. M., \& Bonett, D. G. (1980). Significance tests and goodness of fit in the analysis of covariance structures. Psychological Bulletin, 88(3), 588-606.

Bermingham, A., \& Smeaton, A. F. (2010). Crowdsourced real-world sensing: Sentiment analysis and the real-time web. Paper presented at the AICS Sentiment Analysis Workshop at Artificial Intelligence and Cognitive Science, Galway, Ireland.

Bollen, J., Pepe, A., and Mao, H. (2011). Modeling public mood and emotion: Twitter sentiment and socio-economic phenomena. In Proceedings of the Fifth International AAAI Conference on Weblogs and Social Media, Barcelona, Spain.

Boyd, D., Golder, S., \& Lotan, G. (2010). Tweet, tweet, retweet: Conversational aspects of retweeting on twitter. Paper presented at the Proceedings of the 43rd Hawaii International Conference on System Sciences, Honolulu, HI.

Brain Statistic Research Institute. (2015). Twitter Statistics, from http://www.statisticbrain.com/twitter-statistics/

Cambria, E. (2016). Affective computing and sentiment analysis. IEEE Intelligent Systems, 31(2), 102-107.

Cambria, E., Howard, N., Xia, Y., \& Chua, T.-S. (2016). Computational intelligence for big social data analysis. IEEE Computational Intelligence Magazine, 11(3), 8-9.

Castillo, C., Mendoza, M., \& Poblete, B. (2013). Predicting information credibility in time-sensitive social media. Internet Research, 23(5), 560-588.

Celli, F., Ghosh, A., Alam, F., \& Riccardi, G. (2016). In the mood for sharing contents: Emotions, personality and interaction styles in the diffusion of news. Information Processing \& Management, 52(1), 93-98. 
Chai, S., Das, S., \& Rao, H. R. (2011). Factors affecting bloggers' knowledge sharing: An investigation across gender. Journal of Management Information Systems, 28(3), 309-342.

Choi, M., \& Toma, C. L. (2014). Social sharing through interpersonal media: Patterns and effects on emotional well-being. Computers in Human Behavior, 36, 530-541.

Cross, C. P., Copping, L. T., \& Campbell, A. (2011). Sex differences in impulsivity: A meta-analysis. Psychological Bulletin, 137(1), 97-130.

Davis, R., \& Sajtos, L. (2009). Anytime, anywhere: Measuring the uniquitous consumer's impulse purchase behavior. International Journal of Mobile Marketing, 4(1), 15-22.

DeLone, W. H., \& McLean, E. R. (1992). Information systems success: The quest for the dependent variable. Information Systems Research, 3(1), 60-95.

Demirbas, M., Bayir, M. A., Akcora, C. G., Yilmaz, Y. S., \& Ferhatosmanoglu, H. (2010). Crowd-sourced sensing and collaboration using twitter. Paper presented at the 2010 IEEE International Symposium on a World of Wireless Mobile and Multimedia Networks (WoWMoM), Montreal, QC, Canada.

Eagly, A. H. (1987). Sex Differences in Social Behavior: A Social-Role Interpretation. Hillsdale, New Jersey: Lawrence Erlbaum Associates.

Eroglu, S. A., Machleit, K. A., \& Davis, L. M. (2001). Atmospheric qualities of online retailing: A conceptual model and implications. Journal of Business Research, 54(2), 177-184.

Fornell, C., \& Larcker, D. F. (1981). Evaluating structural equation models with unobservable variables and measurement error. Journal of Marketing Research, 18(1), 39-50.

Gao, S., Frejinger, E., \& Ben-Akiva, M. (2011). Cognitive cost in route choice with real-time information: An exploratory analysis. Transportation Research Part A, 45(9), 916-926.

Gefen, D., Rigdon, E. E., \& Straub, D. (2011). An update and extension to SEM guidelines for administrative and social science research. MIS Quarterly, 35(2), Iii-Xiv.

Glynn, C. J., Herbst, S., Keefe, G. J. O., \& Shapiro, R. Y. (1999). Public Opinion. Boulder, CO: Westview Press.

Goh, K.-Y., Heng, C.-S., \& Lin, Z. (2013). Social media brand community and consumer behavior: Quantifying the relative impact of user-and marketer-generated content. Information Systems Research, 24(1), 88-107.

Graa, A., \& Dani-elKebir, M. (2012). Application of stimulus \& response model to impulse buyin behavior of Algerian consumers. Serbian Journal of Management, 7(1), 53-64.

Hair, J. F., Black, W. C., Babin, B. J., \& Anderson, R. E. (2006). Multivariate Data Analysis ( $7^{\text {th }}$ ed.). Englewood Cliffs, NJ: Prentice Hall

Hofmann, W., Friese, M., \& Strack, F. (2009). Impulse and self-control from a dual-systems perspective. Perspectives on Psychological Science, 4(2), 162-176. 
Holmberg, K., \& Hellsten, I. (2015). Gender differences in the climate change communication on Twitter. Internet Research, 25(5), 811-828.

Howard, J. A., \& Sheth, J. N. (1969). The Theory of Buyer Behavior. New York: John Wiley \& Sons, Inc.

Hsi-Peng, L., Chuan-Chuan Lin, J., Kuo-Lun, H., \& Li-Ting, C. (2010). Information sharing behaviour on blogs in Taiwan: Effects of interactivities and gender differences. Journal of Information Science, 36(3), 401-416.

Huberman, B. A., Romero, D. M., \& Wu, F. (2009). Social networks that matter: Twitter under the microscope. First Monday, 14(1), 1-9.

Hui, M. K., \& Bateson, J. E. (1991). Perceived control and the effects of crowding and consumer choice on the service experience. Journal of Consumer Research, 18(2), 174-184.

Hyo-Jung, C., Eckman, M., \& Ruoh-Nan, Y. (2011). Application of the Stimulus-Organism-Response model to the retail environment: The role of hedonic motivation in impulse buying behavior. International Review of Retail, Distribution \& Consumer Research, 21(3), 233-249.

Joly, A., Maret, P., \& Daigremont, J. (2010). Between social awareness and productivity: Results of a survey about real-time microblogging. First Monday, 15(11).

Kacen, J. J., \& Lee, J. A. (2002). The influence of culture on consumer impulsive buying behavior. Journal of Consumer Psychology, 12(2), 163-176.

Katz, E., Haas, H., \& Gurevitch, M. (1973). On the use of the mass media for important things. American Sociological Review, 38(2), 164-181.

Keil, M., Tan, B. C., Wei, K.-K., Saarinen, T., Tuunainen, V., \& Wassenaar, A. (2000). A cross-cultural study on escalation of commitment behavior in software projects. MIS Quarterly, 299-325.

Kim, A. J., \& Ko, E. (2012). Do social media marketing activities enhance customer equity? An empirical study of luxury fashion brand. Journal of Business Research, 65(10), 1480-1486.

Kwak, H., Lee, C., Park, H., \& Moon, S. (2010). What is Twitter, a social network or a news media? Paper presented at the Proceedings of the 19th International Conference on World Wide Web, Raleigh, North Carolina.

Lee, C. S., \& Ma, L. (2012). News sharing in social media: The effect of gratifications and prior experience. Computers in Human Behavior, 28(2), 331-339.

Lee, S., \& Cho, M. (2011). Social media use in a mobile broadband environment: Examination of determinants of Twitter and Facebook use. International Journal of Mobile Marketing, 6(2), 71-87.

Ling, K., Beenen, G., Ludford, P., Wang, X., Chang, K., Li, X., Rashid, A. M. (2005). Using social psychology to motivate contributions to online communities. Journal of Computer-Mediated Communication, 10(4), 1-30.

Liu, Y., \& Shrum, L. (2002). What is interactivity and is it always such a good thing? Implications of definition, person, and situation for the influence of interactivity on advertising effectiveness. Journal of Advertising, 31(4), 53-64. 
Lu, H.-P., \& Hsiao, K.-L. (2009). Gender differences in reasons for frequent blog posting. Online Information Review, 33(1), 135-156.

Machleit, K. A., Eroglu, S. A., \& Mantel, S. P. (2000). Perceived retail crowding and shopping satisfaction: What modifies this relationship? Journal of Consumer Psychology, 9(1), 29-42.

Malik, A., Dhir, A., \& Nieminen, M. (2016). Uses and gratifications of digital photo sharing on Facebook. Telematics and Informatics, 33(1), 129-138.

Marwick, A. E., \& Boyd, D. (2011). I tweet honestly, I tweet passionately: Twitter users, context collapse, and the imagined audience. New Media \& Society, 13(1), 114-133.

McLure Wasko, M., \& Faraj, S. (2000). "It is what one does": Why people participate and help others in electronic communities of practice. The Journal of Strategic Information Systems, 9(2), 155-173.

McMillan, S. J., \& Hwang, J.-S. (2002). Measures of perceived interactivity: An exploration of the role of direction of communication, user control, and time in shaping perceptions of interactivity. Journal of Advertising, 31(3), 29-42.

Mehrabian, A., \& Russell, J. A. (1974). An Approach to Environmental Psychology. Cambridge, MA, US: The MIT Press.

Mick, D. G., \& DeMoss, M. (1990). Self-gifts: Phenomenological insights from four contexts. Journal of Consumer Research, 17(3), 322-332.

Munar, A. M., \& Jacobsen, J. K. S. (2014). Motivations for sharing tourism experiences through social media. Tourism Management, 43, 46-54.

Nagarajan, M., Purohit, H., and Sheth, A. (2010). A qualitative examination of topical tweet and retweet practices. Proceedings of the Fourth International AAAI Conference on Weblogs and Social Media. Palo Alto, CA.

Oh, S., \& Syn, S. Y. (2015). Motivations for sharing information and social support in social media: A comparative analysis of Facebook, Twitter, Delicious, YouTube, and Flickr. Journal of the Association for Information Science and Technology, 66(10), 2045-2060.

Park, S. B., \& Chung, N. (2011). Mediating roles of self-presentation desire in online game community commitment and trust behavior of Massive Multiplayer Online Role-Playing Games. Computers in Human Behavior, 27(6), 2372-2379.

Pedersen, S., \& Macafee, C. (2007). Gender differences in British blogging. Journal of Computer-Mediated Communication, 12(4), 1472-1492.

Rangel, F., \& Rosso, P. (2016). On the impact of emotions on author profiling. Information Processing \& Management, 52(1), 73-92.

Richter, F. (2013). Top 15\% of Twitter users account for $85 \%$ of all tweets. Retrieved September, $\quad 15$ th, from http://www.statista.com/chart/1098/distribution-of-of-tweets-among-twitter-us ers/

Rook, D. W. (1987). The buying impulse. Journal of Consumer Research, 14(2), 189-199. 
Rook, D. W., \& Gardner, M. P. (1993). In the mood: Impulse buying's affective antecedents. Research in Consumer Behavior, 6(7), 1-28.

Rook, D. W., \& Hoch, S. J. (1985). Consuming impulses. Advances in Consumer Research, 12(1), 23-27.

Rosenstiel, T., Sonderman, J., Loker, K., Ivancin, M., \& Kjarval, N. (2015). Twitter and the news: How people use the social network to learn about the world, from

http://www.americanpressinstitute.org/publications/reports/survey-research/ho w-people-use-twitter-news/

Rosso, P., Bosco, C., Damiano, R., Patti, V., \& Cambria, E. (2016). Emotion and sentiment in social and expressive media. Information Processing \& Management, 52(1), 1-4.

Sakaki, T., Okazaki, M., \& Matsuo, Y. (2010, April 26-30). Earthquake shakes Twitter users: Real-time event detection by social sensors. Paper presented at the Proceedings of the 19th international conference on World wide web, Raleigh, North Carolina.

Segars, A. H., \& Grover, V. (1993). Re-examining perceived ease of use and usefulness. MIS Quarterly, 17(4), 517-525.

Singh, V. K., Gao, M., \& Jain, R. (2010). From microblogs to social images: Event analytics for situation assessment. Paper presented at the Proceedings of The International Conference on Multimedia Information Retrieval, New York.

Stieglitz, S., \& Dang-Xuan, L. (2013). Emotions and information diffusion in social media-Sentiment of microblogs and sharing behavior. Journal of Management Information Systems, 29(4), 217-248.

Stokols, D. (1972). On the distinction between density and crowding: Some implications for future research. Psychological Review, 79(3), 275-277.

Strack, F., Werth, L., \& Deutsch, R. (2006). Reflective and impulsive determinants of consumer behavior. Journal of Consumer Psychology 16(3), 205-216.

Taylor, W. A. (2004). Computer-mediated knowledge sharing and individual user differences: An exploratory study. European Journal of Information Systems, 13(1), 52-64.

Thelwall, M., Buckley, K., \& Paltoglou, G. (2011). Sentiment in Twitter events. Journal of the American Society for Information Science \& Technology, 62(2), 406-418.

Tobias, E. (2011). Using Twitter and other social media platforms to provide situational awareness during an incident. Journal of Business Continuity \& Emergency Planning, 5(3), 208-223.

Trainor, K. J., Andzulis, J. M., Rapp, A., \& Agnihotri, R. (2014). Social media technology usage and customer relationship performance: A capabilities-based examination of social CRM. Journal of Business Research, 67(6), 1201-1208.

Venkatesh, V., \& Morris, M. G. (2000). Why don't men ever stop to ask for directions? Gender, social influence, and their role in technology acceptance and usage behavior. MIS Quarterly, 24(1), 115-139. 
Verhagen, T., \& van Dolen, W. (2011). The influence of online store beliefs on consumer online impulse buying: A model and empirical application. Information \& Management, 48(8), 320-327.

Verplanken, B., Herabadi, A. G., Perry, J. A., \& Silvera, D. H. (2005). Consumer style and health: The role of impulsive buying in unhealthy eating. Psychology \& Health, 20(4), 429-441.

Walton, S. C., \& Rice, R. E. (2013). Mediated disclosure on Twitter: The role of gender and identity in boundary impermeability, valence, disclosure, and stage. Computers in Human Behavior, 29, 1465-1474.

Wang, C., Jin, X.-L., Lee, M. K., Fang, Y., Zhou, Z., \& Hua, Z. (2013). Understanding status update in microblog: A perspective on media needs. Paper presented at the Proceedings of the 17th Pacific Asia Conference on Information Systems, Jeju Island, Korea.

Wang, C., Jin, X.-L., Zhou, Z., Fang, Y., Lee, M. K., \& Hua, Z. (2015). Effect of perceived media capability on status updates in microblogs. Electronic Commerce Research and Applications, 14(3), 181-191.

Wang, D., Park, S., \& Fesenmaier, D. R. (2012). The role of smartphones in mediating the touristic experience. Journal of Travel Research, 51(4), 371-387.

Wang, R. Y., \& Strong, D. M. (1996). Beyond accuracy: What data quality means to data consumers. Journal of Management Information Systems, 12(4), 5-33.

Weafer, J., \& de Wit, H. (2014). Sex differences in impulsive action and impulsive choice. Addictive Behaviors, 39(11), 1573-1579.

Weiser, E. B. (2000). Gender differences in Internet use patterns and Internet application preferences: A two-sample comparison. CyberPsychology and Behavior, 3(2), 167-178.

Wexler, A. (2014). Twitter is the 21st century newspaper. Retrieved December 1st, 2015 ,

http://www.huffingtonpost.com/adam-wexler/twitter-is-the-21st-centu_b_4774 976.html

Zhang, K. Z., Benyoucef, M., \& Zhao, S. J. (2015). Consumer participation and gender differences on companies' microblogs: A brand attachment process perspective. Computers in Human Behavior, 44, 357-368.

Zhang, P. (2013). The affective response model: A theoretical framework of affective concepts and their relationships in the ICT context. MIS Quarterly, 37(1), 247-274.

Zhao, D., \& Rosson, M. B. (2009). How and why people Twitter: The role that micro-blogging plays in informal communication at work. Paper presented at the In GROUP '09: Proceedings of the ACM 2009 International Conference on Supporting group work, New York, NY, USA.

Zhao, L., \& Lu, Y. (2012). Enhancing perceived interactivity through network externalities: An empirical study on micro-blogging service satisfaction and continuance intention. Decision Support Systems, 53(4), 825-834. 